\title{
Radiculopathy with concomitant sacroiliac dysfunction and lumbosacral degenerative disease: illustrative case
}

\author{
Jeffrey D. Oliver, MD, ${ }^{1}$ Noah L. Lessing, BS, ${ }^{2}$ Harry M. Mushlin, MD, ${ }^{3}$ Joshua R. Olexa, MD, ${ }^{1}$ Kenneth M. Crandall, MD, ${ }^{1}$ and \\ Charles A. Sansur, MD, MHSc ${ }^{1}$ \\ ${ }^{1}$ Department of Neurosurgery, University of Maryland Medical Center, Baltimore, Maryland; ${ }^{2}$ University of Maryland School of Medicine, Baltimore, Maryland; and ${ }^{3}$ Department \\ of Neurosurgery, University of Pittsburgh Medical Center, Pittsburgh, Pennsylvania
}

\begin{abstract}
BACKGROUND The sacroiliac joint (SIJ) is an important cause of low back pain and referred leg pain (RLP). Pain from SIJ dysfunction may occur in isolation or may result from a combination with lumbosacral area-mediated pain. SIJ fusion is one treatment modality for medically refractory symptoms and may also have a role in the treatment of RLP.

OBSERVATIONS The authors present a challenging case of concomitant lumbosacral degenerative disease and SIJ dysfunction in a patient with radiculopathy. They provide clinical characteristics and imaging findings and discuss difficulties in dealing with the intersection of these two distinct diagnoses. In addition, the authors offer a review of the relevant literature, elucidating the role of SIJ dysfunction in causing radicular lower extremity pain, the relationship to concomitant lumbosacral degenerative disease, and outcome data for SIJ fusion as it relates to RLP.

LESSONS With increasing numbers of patients undergoing spinal instrumentation in the setting of degenerative lumbosacral arthritis, as well as randomized controlled trial data demonstrating the efficacy of SIJ fusion for medically refractory SIJ dysfunction, it is important to recognize the challenges in understanding how both of these patient groups may present with radiculopathy. Failure to do so may result in incorrect patient selection, poor outcomes, and increased morbidity for at-risk patients.
\end{abstract}

https://thejns.org/doi/abs/10.3171/CASE21102

KEYWORDS sacroiliac joint; radiculopathy; fusion; sciatica

The sacroiliac joint (SIJ) has regained interest as one etiology for sciatica-like radicular pain of the lower extremity. One of the earliest case series, from 1928 by Yeoman et al., ${ }^{1}$ described 100 patients with this entity, but later experience directed interest toward lumbosacral etiologies and degenerative disc disease as causative for many patients with radiculopathy. ${ }^{2}$

There has been renewed interest in SIJ-related leg pain in anatomical study ${ }^{3}$ and in multiple case series. ${ }^{4-6}$ SIJ dysfunction and leg pain can be managed nonsurgically with injections, radiofrequency ablation, or physical therapy. ${ }^{7,8}$ Data derived from both retrospective cohorts and now randomized controlled trials (RCTs) indicate that patients with lower extremity pain can have improvement in referred leg pain (RLP) and other quality of life (QOL) metrics after SIJ fusion when compared with nonsurgical cohorts. $^{9-11}$ One cohort of patients with RLP in these studies comprises those with distal, lower leg pain secondary to L5 and S1 radiculopathy.

An area in which these and other studies fall short is understanding patients who present with concomitant SIJ dysfunction and lumbosacral degenerative disease. We present a challenging case of medically refractory radiculopathy in a patient with these intersecting diagnoses. We describe her clinical course, imaging findings, and surgical outcomes. In addition, we offer a review of the relevant literature regarding SIJ dysfunction and RLP, concomitant lumbosacral degenerative disease, and outcomes after SIJ fusion.

ABBREVIATIONS CT = computed tomography; iMIA = iFuse Implant System Minimally Invasive Arthrodesis; QOL = quality of life; RCT = randomized controlled trial; $\mathrm{RLP}=$ referred leg pain; SIJ = sacroiliac joint.

INCLUDE WHEN CITING Published September 20, 2021; DOI: 10.3171/CASE21102.

SUBMITTED February 16, 2021. ACCEPTED July 27, 2021.

(c) 2021 The authors, CC BY-NC-ND 4.0 (http://creativecommons.org/licenses/by-nc-nd/4.0/). 


\section{Illustrative Case}

A 49-year-old woman with a past medical history of type 2 diabetes presented with 1 year of worsening low back pain and radiating, bilateral, posterolateral leg pain. Her physical examination disclosed that she was neurologically intact with full strength in her upper and lower extremities bilaterally. She ambulated independently without difficulty. Magnetic resonance imaging of the lumbar spine revealed degenerative disc disease with a superimposed L5-S1 disc herniation (Fig. 1), foraminal stenosis, and loss of lumbar lordosis. After failing maximum conservative therapy, she underwent an L5-S1 anterior lumbar interbody fusion.

During her postoperative recovery, she continued to experience radicular symptoms and axial back pain for several months. The finding of follow-up computed tomography (CT) was concerning for possible pseudoarthrosis, and an L5-S1 posterolateral fusion was performed 6 months after her index surgery in order to provide a direct L5-S1 foraminal decompression with additional fixation for increased stability (Fig. 2). Despite evidence of adequate decompression and fusion on follow-up, the patient's pain persisted, with worsening right posterior leg pain, foot numbness, and lower back pain. Further evaluation indicated that she had developed tenderness to palpation of the right SIJ. Upon examination, she demonstrated a positive Patrick's sign on the right, noted by exacerbation of her right SIJ pain upon flexion, abduction, and external rotation of the right hip while the examiner applied a posteriorly directed force on the medial aspect of the ipsilateral knee with the pelvis stabilized in a supine position (flexion, abduction, and external rotation test). Imaging in the form of a CT scan showed degenerative changes of the right SIJ greater than the left SIJ (Fig. 3). She was offered therapeutic and diagnostic injections to help confirm the diagnosis of SIJ dysfunction, but due to her previous inability to tolerate injections and her medical comorbidities, she elected to forgo this modality. She completed a 12-week course of physical therapy, including aquatherapy, but continued to have progressive symptoms. Given her

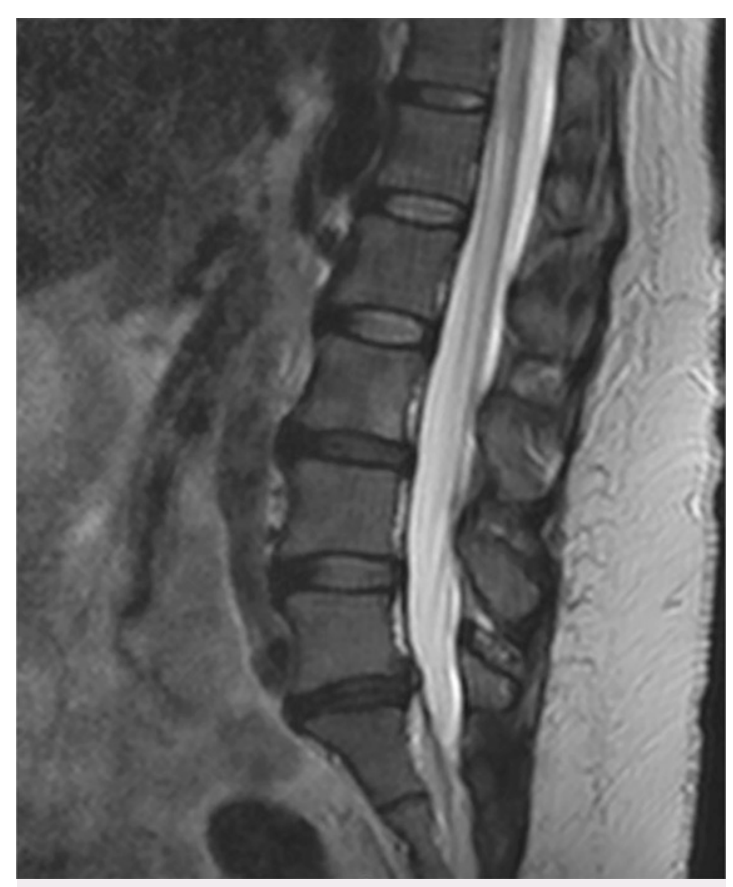

FIG. 1. Preoperative T2 sagittal magnetic resonance imaging showing L5-S1 disc herniation and loss of disc height.

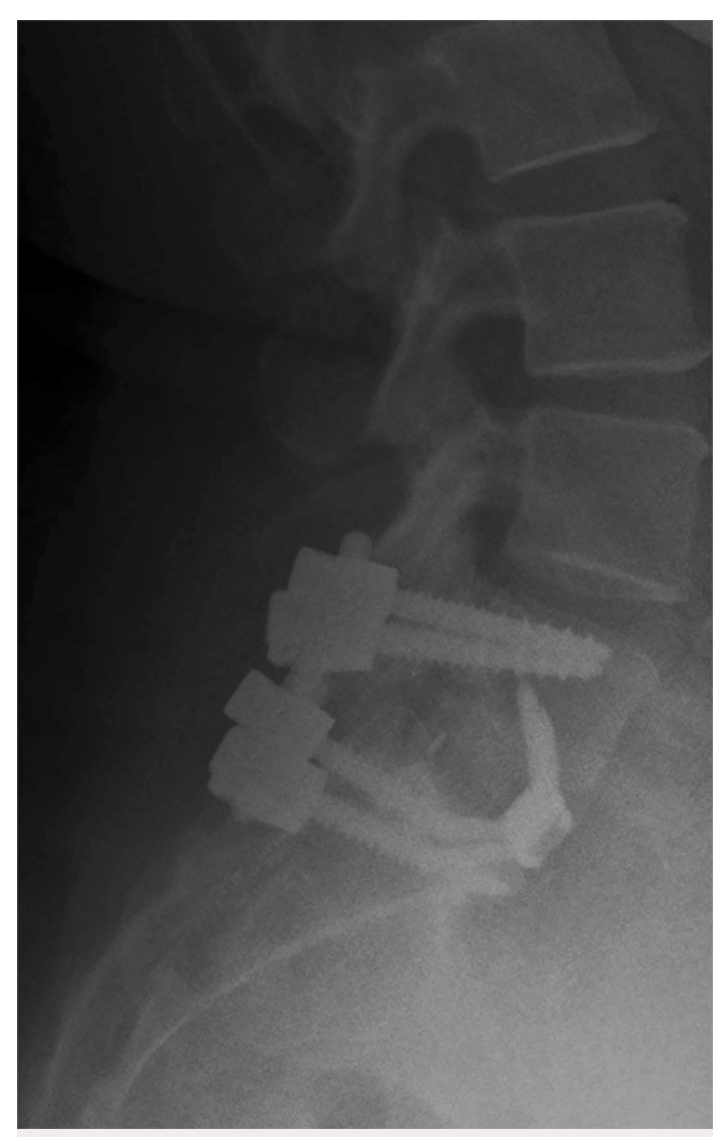

FIG. 2. Postoperative lateral radiographs after anterior lumbar interbody fusion and posterior lumbar decompression and fusion.

examination and imaging findings, the patient was offered and underwent right-sided minimally invasive SIJ fusion after failure of nonsurgical therapy, and she had significant improvement in her symptoms.

In short-interval follow-up, her right-sided radicular pain was completely resolved, but she continued to experience similar left-sided symptoms. On examination, she was noted to have significant tenderness upon palpation of the left SIJ. In addition, she had a positive compression test result, with pain elicited by the examiner applying downward pressure across the pelvis while the patient was lying in the lateral position with the left SIJ facing upward during slight hip and knee flexion. On the basis of these findings and the success of the right-sided procedure, the patient opted to receive a left-sided SIJ fusion. The left-sided surgery was performed similar to that on the right side. She never experienced resolution of her left-sided symptoms. Given the very positive response to the right-sided surgery, a left-sided revision surgery was scheduled to see if additional iliosacral fixation would result in better symptom control. However, this surgery was canceled due to the patient's unrelated medical comorbidities, and she was managed nonsurgically until last follow-up.

\section{Discussion \\ Observations}

A literature review was conducted to review SIJ dysfunctionrelated radiculopathy, concomitant lumbosacral disease, and published outcomes after SIJ fusion. 


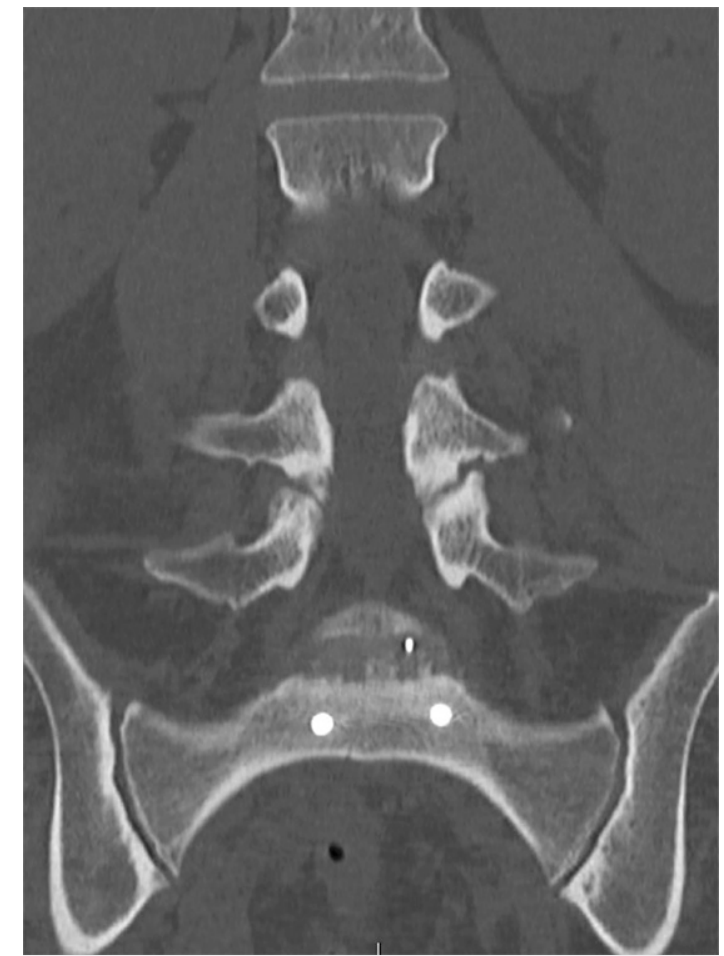

FIG. 3. Coronal lumbar CT showing increased right greater than left cortical bone formation, osteophyte development, and intraarticular sacroiliac joint air.

\section{SIJ and RLP}

The relationship between RLP and SIJ dysfunction has been well established, with pain being most commonly referred to the buttock, groin, thigh, calf, and foot. Approximately $75 \%-89 \%$ of patients with SIJ dysfunction may present with RLP, ${ }^{9,10}$ and groin pain may be as common as $46 \%{ }^{12}$ Buttock pain location may relate to the location of the SIJ dysfunction. ${ }^{13}$

Although proximal buttock, groin, and thigh pain might be attributable to the local inflammatory milieu and referred pain from the SIJ, patients with more distal lower extremity pain represent a different entity. Proposed mechanisms for distal pain have included the focal anatomical relationship between the SIJ capsule and the L5-S1 nerve roots or the leakage of inflammatory substrate into the periarticular space causing irritation of the traversing neural elements of the lumbosacral plexus, as seen with extravasated contrast during SIJ injections. ${ }^{6,14}$ In addition, cases of inferior SIJ osteophytes impinging on the sciatic nerve have also been described as one etiology for more distal pain. ${ }^{15}$

In the iFuse Implant System Minimally Invasive Arthrodesis (iMIA) cohort, $68 \%$ of patients presented with referred pain to the leg. ${ }^{11}$ In another series, Weksler et al. ${ }^{8}$ reported $23 \%$ of patients with RLP to the calf or foot, whereas Visser et al. ${ }^{5}$ reported $41 \%$ of patients presenting with radiating lower leg pain nonattributable to a specific nerve root as being referrable to the SIJ. Slipman et al. ${ }^{16}$ similarly reported $28 \%$ lower leg symptoms related to SIJ disease. One particular challenge in comparing these studies and thus the management of these patients is the lack of clarity and consensus regarding the nature of lower leg pain being referred pain versus radicular pain, attributable to incomplete understanding of the underlying mechanism of pain generation.

\section{SIJ and Concomitant Lumbosacral Disease}

Establishing the diagnosis of SIJ dysfunction remains challenging, and standard recommendations are for the use of multimodal testing, including provocative maneuvers, imaging findings, and diagnostic or therapeutic injections. Concomitant lumbosacral disease may confound these findings or vice versa.

There have been some attempts to understand the coassociation of SIJ and lumbosacral degenerative disease. Galm et al. ${ }^{17}$ reported on a series of 150 patients presenting with low back pain and imaging-proven lumbar disc herniations, with 46 patients (31\%) being found to have evidence of SIJ dysfunction. Similarly, Telli et al. $^{18}$ reported an incidence of SIJ dysfunction of $33.3 \%$ in their cohort of 234 patients with evidence of lumbar disc herniation. This high rate of crossover highlights the need for careful patient evaluation before surgical intervention.

Patients with a prior history of lumbosacral fusion or decompressive surgery might also have a higher incidence of adjacent segment disease at the SIJ in clinical series. ${ }^{19,20}$ Correlated radiographic findings and improvement after injections also indicate propensity for further degeneration of the SIJ after lumbosacral surgery. ${ }^{21,22}$ Finally, biomechanical data indicate that long-segment fusion to S1 may predispose to adjacent segment changes in the SIJ. ${ }^{23}$

\section{Outcomes After SIJ Fusion}

Improvement of lower extremity complaints related to SIJ dysfunction has been reported in previous clinical series for both medical and surgical cohorts. ${ }^{4,15}$ Nonsurgical therapy for SIJ-related leg pain has also been shown to be successful in an RCT. ${ }^{7}$

Surgical outcomes from RCTs have focused primarily on metrics related to pain, functionality, and QOL. Significant improvement in these metrics has been shown in two RCTs for patients undergoing SIJ fusion compared with medical management. ${ }^{9,10}$ In the Investigation of Sacroiliac Fusion Treatment trial, the authors did not note a difference in patients with or without a prior history of spinal fusion compared with a medical cohort. ${ }^{9}$ Unfortunately, there is limited analysis of leg pain outcomes from this cohort.

Patients included in the MIA studies specifically did not have a history of having undergone a prior spinal fusion. In a subgroup analysis of patients in the iMIA study, the authors reported significant improvement in RLP and QOL metrics. In their limited 6-month follow-up, they did not find an association with the type of RLP and response to SIJ fusion. ${ }^{10,11}$

Limited data exist on outcomes for patients undergoing SIJ fusion after previous spinal surgery. Schroeder et al. ${ }^{19}$ reported improvement in QOL metrics after SIJ fusion in patients with prior long-segment spinal fusions ending at the sacrum. SIJ fusion might also be associated with certain biomechanical advantages after adjacent spinal surgery to $S 1 .{ }^{23}$ This appears to be an area where further study is needed, especially in cohorts presenting with radicular symptoms.

\section{Lessons}

In the case we present above, we originally diagnosed this patient as having L5-S1 radiculopathy, which seemed appropriate based on the radiographic findings and the dermatomal distribution of her pain. Ultimately, we came to the conclusion that she really had lumbosacral plexus irritation secondary to SIJ dysfunction. 
The most important findings that resulted in this diagnosis were the developing physical examination findings and positive provocative maneuvers. Imaging findings and the clinical course of worsening after an adjacent segment spinal surgery also provided clues to making the diagnosis.

This case is a good representation of how easy it can be to confuse these two processes. Very careful attention needs to be paid in the setting of L5-S1 symptoms and low back pain, regardless of the radiographic appearance of the L5-S1 interspace. SIJ dysfunction should be ruled out for every case of L5-S1 radiculopathy in order to avoid unnecessary surgery. The SIJ can be a significant lower extremity pain generator, and SIJ fusion has been shown to significantly improve symptoms in patients with medically refractory SIJ dysfunction. Concomitant lumbosacral disease may confound the understanding of these patients and has a relatively high incidence. Further large cohort studies are needed to better understand predictors of success for patients with these coinciding conditions, including the role of perioperative imaging, provocative maneuvers, and invasive diagnostic tests.

\section{References}

1. Yeoman W. The relation of arthritis of the sacro-iliac joint to sciatica, with an analysis of 100 cases. Lancet. 1928;212:1119-1122.

2. Mixter WJ, Barr JS. Rupture of the intervertebral disc with involvement of the spinal canal. N Engl J Med. 1934;211:210-215.

3. Ebraheim NA, Lu J, Biyani A, Huntoon M, Yeasting RA. The relationship of lumbosacral plexus to the sacrum and the sacroiliac joint. Am J Orthop. 1997;26(2):105-110.

4. Buijs $E$, Visser L, Groen G. Sciatica and the sacroiliac joint: a forgotten concept. Br J Anaesth. 2007:99(5):713-716.

5. Visser LH, Nijssen PG, Tijssen CC, van Middendorp JJ, Schieving J. Sciatica-like symptoms and the sacroiliac joint: clinical features and differential diagnosis. Eur Spine J. 2013;22(7):1657-1664.

6. Fortin JD, Vilensky JA, Merkel GJ. Can the sacroiliac joint cause sciatica? Pain Physician. 2003;6(3):269-271.

7. Visser LH, Woudenberg NP, de Bont J, et al. Treatment of the sacroiliac joint in patients with leg pain: a randomized-controlled trial. Eur Spine J. 2013;22(10):2310-2317.

8. Weksler N, Velan GJ, Semionov M, et al. The role of sacroiliac joint dysfunction in the genesis of low back pain: the obvious is not always right. Arch Orthop Trauma Surg. 2007;127(10):885-888.

9. Kube RA, Muir JM. Sacroiliac joint fusion: one year clinical and radiographic results following minimally invasive sacroiliac joint fusion surgery. Open Orthop J. 2016;10:679-689.

10. Dengler JD, Kools D, Pflugmacher R, et al. 1-Year results of a randomized controlled trial of conservative management vs. minimally invasive surgical treatment for sacroiliac joint pain. Pain Physician. 2017;20(6):537-550.

11. Dengler J, Sturesson B, Kools $D$, et al. Referred leg pain originating from the sacroiliac joint: 6-month outcomes from the prospective randomized controlled iMIA trial. Acta Neurochir (Wien). 2016; 158(11):2219-2224.

12. Kurosawa D, Murakami E, Aizawa T. Groin pain associated with sacroiliac joint dysfunction and lumbar disorders. Clin Neurol Neurosurg. 2017;161:104-109.

13. Kurosawa D, Murakami E, Aizawa T. Referred pain location depends on the affected section of the sacroiliac joint. Eur Spine J. 2015;24(3):521-527.
14. Fortin JD, Washington WJ, Falco FJ. Three pathways between the sacroiliac joint and neural structures. AJNR Am J Neuroradiol. 1999;20(8):1429-1434.

15. Kumar B, Sriram KG, George C. Osteophyte at the sacroiliac joint as a cause of sciatica: a report of four cases. $J$ Orthop Surg (Hong Kong). 2002;10(1):73-76.

16. Slipman CW, Jackson HB, Lipetz JS, Chan KT, Lenrow D, Vresilovic EJ. Sacroiliac joint pain referral zones. Arch Phys Med Rehabil. 2000;81(3):334-338.

17. Galm R, Fröhling M, Rittmeister M, Schmitt E. Sacroiliac joint dysfunction in patients with imaging-proven lumbar disc herniation. Eur Spine J. 1998;7(6):450-453.

18. Telli $H$, Hüner $B$, Kuru Ö. Determination of the prevalence from clinical diagnosis of sacroiliac joint dysfunction in patients with lumbar disc hernia and an evaluation of the effect of this combination on pain and quality of life. Spine (Phila Pa 1976). 2020;45(8):549-554.

19. Schroeder JE, Cunningham ME, Ross T, Boachie-Adjei O. Early results of sacro-iliac joint fixation following long fusion to the sacrum in adult spine deformity. HSS J. 2014;10(1):30-35.

20. Ha KY, Lee JS, Kim KW. Degeneration of sacroiliac joint after instrumented lumbar or lumbosacral fusion: a prospective cohort study over five-year follow-up. Spine (Phila Pa 1976). 2008; 33(11):1192-1198.

21. Onsel C, Collier BD, Kir KM, et al. Increased sacroiliac joint uptake after lumbar fusion and/or laminectomy. Clin Nucl Med. 1992;17(4): 283-287.

22. Liliang PC, Lu K, Liang CL, Tsai YD, Wang KW, Chen HJ. Sacroiliac joint pain after lumbar and lumbosacral fusion: findings using dual sacroiliac joint blocks. Pain Med. 2011;12(4): 565-570.

23. Mushlin $\mathrm{H}$, Brooks DM, Olexa J, et al. A biomechanical investigation of the sacroiliac joint in the setting of lumbosacral fusion: impact of pelvic fixation versus sacroiliac joint fixation. $J$ Neurosurg Spine. 2019;31(4):562-567.

\section{Disclosures}

Dr. Crandall reported nonfinancial support from Stryker outside the submitted work. Dr. Sansur reported "other" from Stryker Spine and "other" from Nuvasive outside the submitted work. The other authors report no conflict of interest concerning the materials or methods used in this study or the findings specified in this paper.

\section{Author Contributions}

Conception and design: Oliver, Mushlin, Sansur. Acquisition of data: Oliver, Lessing, Mushlin, Sansur. Analysis and interpretation of data: Oliver, Lessing, Olexa, Crandall, Sansur. Drafting the article: Oliver, Lessing, Mushlin, Olexa, Sansur. Critically revising the article: Oliver, Mushlin, Olexa, Crandall, Sansur. Reviewed submitted version of manuscript: Oliver, Mushlin, Olexa, Crandall, Sansur. Approved the final version of the manuscript on behalf of all authors: Oliver.

Administrative/technical/material support: Oliver. Study supervision: Crandall, Sansur.

\section{Correspondence}

Jeffrey D. Oliver: University of Maryland Medical Center, Baltimore, MD. joliver@som.umaryland.edu. 